Eixo Temático: Desenvolvimento de Estratégias Didáticas

\title{
ET-07-013 \\ OLIMPÍADA ESCOLAR COMO FERRAMENTA PARA A CRIAÇÃO DE ESPAÇOS SUSTENTÁVEIS EM AMBIENTE ESCOLAR
}

Niedja Israely da Silva Buarque', Paloma Eduarda de Jesus Silva², Niedja Duarte de Lira³, Janaina Pauline de Araujo ${ }^{4}$

${ }^{1}$ Graduanda em Ciências Biológicas pela UNICAP. Email: niedja.israely@gmail.com

${ }^{2}$ Graduada em Ciências Biológicas pela UFPE.

${ }^{3}$ Graduada em Ciências Biológicas pela UNICAP.

${ }^{4}$ Prefeitura Municipal do Ipojuca.

http://dx.doi.org/10.21472/congrebio2016.et-07-013

\section{RESUMO}

O presente estudo teve como objetivo trabalhar o tema espaços sustentáveis em escolas da rede pública do Município de Ipojuca/PE, através de uma olimpíada escolar como estratégia didática. A olimpíada teve duração de 6 meses e foi desenvolvida em 10 escolas do ensino fundamental, sendo dividida em 4 etapas onde em cada uma, os alunos precisavam desenvolver tarefas como, por exemplo, a elaboração de mascotes com materiais reciclados, a elaboração de estudo do meio, tendo como finalidade o diagnóstico da situação da escola, finalizando com a construção de um recanto sustentável na escola com base nos resultados do estudo e com o auxílio dos professores, integrando a comunidade do entorno.

Palavras-chave: Prática socioambiental; Educação Ambiental; Ipojuca.

\section{INTRODUÇÃO}

Em um mundo onde se fala tanto em mudanças climáticas, desmatamento, falta de saneamento e doenças desencadeadas por esse problema é necessário uma atenção da gestão pública em iniciar um gerenciamento voltado para o planejamento sustentável onde possa em equilíbrio atender a demanda da população, as questões sociais, e ainda contemple a face econômica, atendendo em conjunto o eixo ambiental.

A escola, como ambiente formal de ensino, é um dos principais lugares para trabalhar a temática sustentabilidade. Esta desempenha um importante papel como formadora de cidadãos, sendo de grande valia ainda na fase escolar, desenvolver o pensamento voltado para essas questões.

As principais atividades em projetos de educação ambiental são de caráter lúdico, promovendo o prazer em aprender (BASTOS et al., 2005). A criação de uma olimpíada que visa trabalhar a sustentabilidade nas escolas tem como proposta unir o conhecimento e desenvolvimento do lúdico dos alunos da rede municipal de ensino.

Segundo Borges (2011) ao se trabalhar espaços sustentáveis no ambiente escolar, pretende-se estimular que as escolas se identifiquem com os ideais de sustentabilidade, compreendam a importância de transformar suas atitudes e também seus objetivos de ensino e aprendizagem, tornando-se por fim referências de sustentabilidade para seus alunos e a comunidade. As sementes plantadas na escola servem como fonte de inspiração e estímulo para a transformação do dia a dia dos que se alimentam delas. Esse é o caminho em que podemos apostar para promover a transformação de percepções, posturas e atitudes, com o intuito de construir sociedades sustentáveis. 


\section{OBJETIVOS}

Disseminar nas escolas municipais do Ipojuca boas práticas socioambientais e ações de sustentabilidade envolvendo toda a comunidade escolar, famílias e moradores do entorno das escolas.

\section{METODOLOGIA}

O presente projeto foi idealizado pela Secretaria de Meio Ambiente e Controle Urbano do município de Ipojuca, que está localizado na Região Metropolitana de Recife, com uma população estimada de 91.341 habitantes e uma área territorial de aproximadamente 527,107 $\mathrm{km}^{2}$ (IBGE, 2015).

Para a realização da olimpíada foram selecionadas 10 escolas municipais, que oferecem educação do $6^{\circ}$ ao $9^{\circ}$ ano do Ensino Fundamental. Os alunos que participaram das atividades foram eleitos pelas escolas, sendo cada coletivo formado por 15 estudantes. A apresentação e execução do cumprimento das tarefas foram realizadas em quatro etapas sendo a última durante o evento de encerramento da Olimpíada, que foi denominada "Sementes de Sustentabilidade". Os alunos eram todos reunidos em um único local para apresentação dos trabalhos. Em 2015 foi realizado o $3^{\circ}$ ano do evento entre os meses de junho a dezembro.

Na primeira etapa da olimpíada foi solicitado que os alunos criassem uma identidade para a equipe, deveria ser escolhido um nome relacionado com o tema sustentabilidade e um mascote utilizando material reciclável, bem como, fazer um cartaz com o nome do coletivo. Além disso, deveriam realizar uma estratégia de marketing e comunicação, criar e dramatizar um "slogan"/grito de guerra da equipe, promovendo a Escola Sustentável e a Olimpíada Sementes de Sustentabilidade.

Na segunda etapa, os alunos tiveram que realizar o Estudo do Meio - Mapa Falado do ambiente escolar e comunidade do entorno. Neste estudo, os principais aspectos a serem observados eram os seguintes pontos: áreas verdes, resíduos sólidos, relatos do mutirão para instalação do recanto sustentável da escola, uso de materiais recicláveis, reuso de água, redução do consumo de energia. A realização das atividades deveria ser fotografada, registrada e apresentada pelos alunos, no dia da apresentação da II etapa.

Na terceira etapa, com base no nome da equipe, no mascote produzido e nos resultados do Estudo do Meio, o coletivo de jovem apresentaria uma peça teatral com a temática "escola sustentável”, tendo o tempo máximo de apresentação de 15 minutos.

Na quarta e última etapa das Olimpíadas Sementes de Sustentabilidade, os estudantes apresentaram a produção do "Recanto de Sustentabilidade da Escola", juntamente com o passo a passo da montagem e criação do referido Espaço. Os critérios de pontuação utilizados nesta etapa foram: capacidade de pesquisa, estudo, consulta aos moradores mais antigos, empenho, compromisso, responsabilidade, o estado de vitalidade do recanto e uso por todos da comunidade escolar, o uso de material reciclável e a participação da comunidade e familiares.

A comissão julgadora de todo evento foi formada por servidores das Secretarias municipais, e membros de órgãos que desenvolvem projetos ambientais instalados no Município. De um modo geral, os critérios de avaliação utilizados nas três primeiras etapas foram: relação com o tema sustentabilidade, criatividade e originalidade, uso de materiais recicláveis e reutilizados, visual/acabamento e capricho na finalização, organização da apresentação/trabalho em equipe e autonomia dos alunos.

Após o termino da gincana, foram somadas as pontuações da comissão fazendo assim uma média aritmética para cada atividade, sendo posteriormente somadas as medias encontradas, obtendo-se assim o resultado final. 


\section{RESULTADOS E DISCUSSÃO}

No decorrer das olimpíadas, os alunos desenvolveram as atividades com entusiasmo e dedicação, conseguiram elaborar todas as etapas de forma eficiente e, em sua maioria, todos conseguiram atender aos requisitos solicitados. Todas as escolas criaram recantos sustentáveis no ambiente escolar, de um modo geral, a comunidade aproveitou áreas que não estavam sendo utilizadas e criaram hortas e jardins, e os alunos se tornaram responsáveis pela manutenção do ambiente.

Ao fim da olimpíada, foi aplicado um questionário com os alunos e professores a fim de avaliar a importância do evento. De modo geral, os mestres que acompanharam as olimpíadas relataram que a gincana foi muito importante para a integração da comunidade escolar, bem como, para o desenvolvimento de práticas sustentáveis entre eles, uma vez que houve mudanças de atitude como maior respeito ao ambiente, redução e reutilização de resíduos. Foi perguntado os pontos positivos e negativos das olimpíadas, e no geral, os negativos foram falta de espaço e tempo para desenvolver as atividades. Com relação aos positivos foram o resgate da autoestima e valores dos alunos, participação e conscientização ambiental da comunidade local. Os temas citados como mais relevantes nas atividades foram: o uso dos três R (Reduzir, Reutilizar e Reciclar), Agenda 21, preservação dos recursos naturais, impactos ambientais, química ambiental e biodiversidade.

Quanto a avaliação do aluno em relação a olimpíada, eles afirmaram que foi primordial para conscientizar a todos sobre a importância e preservação do meio ambiente, a necessidade de reduzir, reutilizar e reciclar os produtos, a mudança de atitude em relação ao cuidar do meio ambiente e aprender a trabalhar em equipe. Quando perguntados os pontos positivos e negativos relataram que de positivo houve o trabalho em equipe, a união entre as turmas, a boa recepção dos membros da secretaria, a organização da olimpíada, as novas amizades e o trabalho com a comunidade, conscientizando-os sobre os problemas causados pela poluição. Quanto aos pontos negativos, a rivalidade entre alunos, o tempo longo entre as etapas e a falta de responsabilidade de alguns alunos. Foi perguntado ainda, "Quais praticas que beneficiam o meio ambiente foram adquiridas durante as olimpíadas?” e obtivemos as seguintes respostas, realizar coleta seletiva, reutilizar resíduos sólidos como garrafa pet, conversar com a população sobre os problemas ambientais e suas soluções, não jogar lixo nas ruas, não deixar água parada e reciclagem.

\section{CONCLUSÃO}

A educação ambiental abrange temas diversos e de profunda relevância para a sociedade atual, tais como, socioambiental, sociocultural, saúde pública, resíduos sólidos e preservação ambiental. Por este motivo, este projeto, contou com a participação de várias entidades que se tornaram parceiras, contribuindo para o sucesso do programa, como por exemplo, as Secretarias Municipais de Educação, Juventude e Esportes, Saúde, a Ong Ecoassociados e o laboratório de Aquicultura Marinha Hippocampus.

As atividades escolares feitas de forma criativa e objetiva, integram todo o sistema escolar, trazendo a inserção de conhecimentos e valores de forma dinâmica, ampliando assim, os conhecimentos dos discentes de cada escola.

Durante a duração das Olimpíadas, todo o corpo social escolar foi envolvido, as pessoas residentes no entorno da escola participaram também das atividades, estimulando a presença de pais, responsáveis e comunidade da região para as práticas pedagógicas realizadas na escola. A educação ambiental é um meio prático, dinâmico e eficiente para formação de pessoas críticas, responsáveis e conscientes sobre o meio ambiente e todas as implicações necessárias para a preservação e consequente melhoria da qualidade de vida, sendo um dever de cada gestor estimulá-la. 


\section{REFERÊNCIAS}

BASTOS, F. F.; MACEDO, N. S. S.; MOREIRA, N. M. C. P. A Educação Ambiental no Curso Normal Superior do Instituto Superior de Educação de Santo Antonio de Pádua: um estudo de caso. Santo Antônio de Pádua: Fundação de Apoio à Escola Técnica, 2005. (Monografia).

BORGES, C. Introdução. Espaços Educadores Sustentáveis. Junho, 2011.

IBGE. Instituto Brasileiro de Geografia e Estatística, Censo Demográfico 2015. Disponível em: $<$ http://www.cidades.ibge.gov.br/xtras/perfil.php?lang=\&codmun=260720>. Acesso em: 28 abr. 2016. 